\title{
Influence of Lactation on Plasma Phenobarbital Concentrations in Rats
}

\author{
Masahiro Moriyama ${ }^{1}$, Syoichi Yamashita ${ }^{1}$, Katsushi Furuno ${ }^{1}$, Tomoaki Sato ${ }^{2}$, Haruyo Domoto ${ }^{1}$, \\ Yasuko Yamatogi ${ }^{3}$, Hiromu Kawasaki ${ }^{1}$ and Yutaka Gomita ${ }^{1, *}$ \\ 'Department of Hospital Pharmacy and ${ }^{3}$ Child Neurology, Okayama University Medical School, 2-5-1 Shikata-cho, Okayama 700, Japan \\ ${ }^{2}$ Department of Hospital Pharmacy, Faculty of Medical Sciences, Kyushu University, Fukuoka 812, Japan \\ Received August 19, $1996 \quad$ Accepted December 4, 1996
}

\begin{abstract}
The effect of lactation on the pharmacokinetics of phenobarbital (PB) after delivery was studied in female rats. Non-pregnant animals received $P B 20 \mathrm{mg} / \mathrm{kg} /$ day twice for $6-7$ days before mating, during pregnancy and after delivery. Chronic PB did not significantly influence changes in the body weight of rats after delivery. On the first post-delivery day, the plasma PB concentration in the PB-treated rats was significantly higher than that in PB-treated, non-pregnant rats (non-pregnant rats); and thereafter, it gradually decreased until ablactation on the 20th day. After ablactation, plasma PB concentrations gradually returned to the level before delivery. In PB-treated rats, pharmacokinetic parameters $\left(C_{\max }, A_{U} C_{0-12}\right)$ of PB between 0 and $12 \mathrm{hr}$ after a single oral administration were significantly decreased during lactation. These results suggest that $\mathrm{PB}$ administered during lactation is transferred in part to offspring through maternal milk.
\end{abstract}

Keywords: Phenobarbital, Pharmacokinetics, Lactation, Plasma concentration

The number of epileptic women undergoing treatment and who desire children are increasing. These patients should continue to take antiepileptic drugs during pregnancy, delivery and lactation for seizure control.

After delivery, mothers have been encouraged to nourish their children by breast feeding because of the immunological (1), nutritional (2) and psychological (3) advantages of maternal milk. In addition, breast feeding prevents withdrawal symptoms such as vomiting, restlessness, hyperactivity and tremor, which appear in babies delivered from women taking antiepileptic or sedative drugs (4).

Many investigators have reported the influences of antiepileptic drugs on the offspring of epileptic mother $(5-8)$. The frequency of maternal psychomotor seizures increases during early puerperium (9). However, there are few reports describing the pharmacokinetics of antiepileptic drugs in the mother during lactation (10).

We developed a means of measuring plasma phenobarbital (PB) concentrations in small amounts $(60 \mu \mathrm{l})$ of rat blood, which allows repeated evaluations (11). Using this method, we found that pregnancy itself does not affect the plasma level and pharmacokinetic parameters of $\mathrm{PB}$ during chronic treatment when a fixed dosage is given

\footnotetext{
* To whom correspondence should be addressed.
}

according to maternal body weight (12). In the present study, we examined the pharmacokinetics of PB during lactation in rats.

\section{MATERIALS AND METHODS}

\section{Chemicals}

PB was purchased from Sigma Chemical Co. (St. Louis, MO, USA). For oral administration, PB was suspended in $0.5 \%$ sodium carboxymethylcellulose (CMC). Acetanilide (Wako Pure Chemical Industries, Osaka) was used as an internal standard (IS) and dissolved at a concentration of $2 \mu \mathrm{g} / \mathrm{ml}$ in $50 \%$ methanol. All other reagents were of guaranteed grade.

\section{Animals}

Female Wistar rats weighing 195 to $210 \mathrm{~g}$ at the beginning of the study were obtained from Charles River Japan, Inc. (Atsugi). They were housed in the experimental animal center of Okayama University Medical School at a controlled ambient temperature of $22^{\circ} \mathrm{C}$ with $60 \%$ relative humidity and under a 12 -hr light/dark cycle (light on from 7:00).

\section{Experimental procedure}

Female rats were divided into 3 groups: a) PB-treated 
and undelivered, b) PB-treated and lactating and c) PBuntreated and lactating group. The effect of lactation on the plasma PB level (trough level) before daily administration was compared between groups a and $b$. In addition, the effect of lactation on the pharmacokinetic parameters following PB administration was studied in groups $b$ and $c$. Each animal was measured and PB (20 $\mathrm{mg} / \mathrm{kg}$ ) was weighed by gavage to groups $\mathrm{a}$ and $\mathrm{b}$ twice (at 07:00 and 19:00) every day throughout the experiment. In group c, $0.5 \%$ CMC (vehicle) was orally administered according to the same schedule. Before the administration of PB or vehicle at 07:00, blood was collected from the tail vein into 60- $\mu \mathrm{l}$ capillaries, and plasma $\mathrm{PB}$ concentrations were measured. When the plasma concentrations of PB reached the steady state ( 7 to 10 days after starting administration), female and male rats were mated for 5 days.

Each pregnant rat in groups $\mathrm{a}$ and $\mathrm{b}$ was delivered of 6 to 16 pups. To standardize the amount of lactation, we selected 3 rats, which had given birth to 13 to 16 offspring, for the study of the lactating group. Twenty days after delivery, the pups were weaned.

During early lactation (2-4 days after delivery) and mid lactation (10-11 days after delivery) and after discontinuing of breast feeding ( $2-3$ days after weaning), we examined time-course changes in the plasma PB concentrations from 0 to $12 \mathrm{hr}$ after a single oral administration of PB in both lactating groups $b$ and $c$. Food was withheld for $12 \mathrm{hr}$ before and throughout this experiment.

\section{Determination of plasma $P B$ level}

After centrifugation at $12,000 \mathrm{rpm}$ for $3 \mathrm{~min}$ in a hematocrit centrifuge (Compur M 1100; Compur Electronic GmbH, Munich, Germany), $20 \mu 1$ of plasma with $0.1 \mu \mathrm{g}$ of IS was passed through a Bond Elut cartridge C-18 solid-phase extraction column (1-ml volume, No. 1210-2001; Varian SPP, Harbour City, CA, USA), which was washed twice with $1 \mathrm{ml}$ of methanol and $1 \mathrm{ml}$ of 0.01 $\mathrm{M} \mathrm{KH} \mathrm{PO}_{4}$. The samples were eluted with $250 \mu \mathrm{l}$ of methanol. The eluate $(20 \mu \mathrm{l})$ was applied to a high performance liquid chromatograph (HPLC) system, composed of a pump (type 510; Waters-Millipore, Milford, MA, USA), an automatic sample processor (Type 710B), an ultraviolet monitor (Type 481), and a data module (Type 730). The analytical column was a LiChroCART RP-18e ( $4 \mu \mathrm{m}$ particle size, $4 \times 125 \mathrm{~mm}$; Cica-Merck Co., Tokyo). The mobile phase was a mixture of acetonitrile/0.01 $\mathrm{M} \mathrm{KH}_{2} \mathrm{PO}_{4}(25 / 75, \mathrm{v} / \mathrm{v})$, the flow rate was 0.8 $\mathrm{ml} / \mathrm{min}$, and $\mathrm{PB}$ was detected at $210 \mathrm{~nm}$. The retention times of IS and PB were 4.6 and $7.8 \mathrm{~min}$, respectively.

\section{Pharmacokinetic analysis}

Pharmacokinetic parameters were obtained from the PB plasma concentration-time data from each animal, using a personal computer program for nonlinear least squares regression analysis (MULTI) (13). Time at maximal concentration $\left(T_{\max }\right)$, maximal plasma concentration $\left(C_{\max }\right)$, area under the plasma concentration-time curve from 0 to $12 \mathrm{hr}\left(\mathrm{AUC}_{0-12}\right)$ and mean residence time (MRT) were calculated by standard linear trapezoidal integration.

\section{Statistical analyses}

Results are expressed as means \pm S.E.M. Data were statistically evaluated by the unpaired Student's $t$-test followed by repeated-measurement analysis of variance (ANOVA) between chronically PB treated, lactating and non-lactating groups. The pharmacokinetic parameters were evaluated by the paired Student's $t$-test between the control (no lactation) and three lactation stages (early, mid and after weaning). A value of $\mathrm{P}<0.05$ was considered statistically significant.

\section{RESULTS}

Changes in plasma $P B$ concentrations during chronic administration in lactating and non-lactating rats

Daily PB administration did not affect the body weight of lactating and undelivered rats compared with the untreated control (data not shown). Figure 1 shows changes in plasma PB concentrations (before daily administration) in rats with or without lactation that were chronically treated with PB. As evaluated by repeated ANOVA, the difference between chronically PB-treated, lactating and non-lactating groups was significant $(F=9.351$, $P<0.05$ ). On the first day after delivery, the plasma $P B$ concentration in lactating rats was significantly higher than that in undelivered rats. The elevated plasma PB concentration in the delivered group rapidly decreased on the second day after delivery and thereafter, PB concentrations gradually decreased until ablactation. PB concentrations of the group from 8 to 22 days after delivery were significantly lower than those of the undelivered groups. After weaning on the 20th day after delivery, maternal plasma $\mathrm{PB}$ concentrations gradually returned to levels on the 2nd day after delivery.

\section{Effect of lactation on pharmacokinetics of $P B$}

Figure 2 shows the time-course changes in plasma $P B$ concentrations after a single oral $(20 \mathrm{mg} / \mathrm{kg}$, p.o.) administration of PB during early (2-4 days after delivery) lactation. Plasma $\mathrm{PB}$ concentrations in both chronically PB-treated and untreated rats rapidly increased to a maximum of 31.2 and $16.2 \mu \mathrm{g} / \mathrm{ml}$ at 1 and $2 \mathrm{hr}$, respectively, 


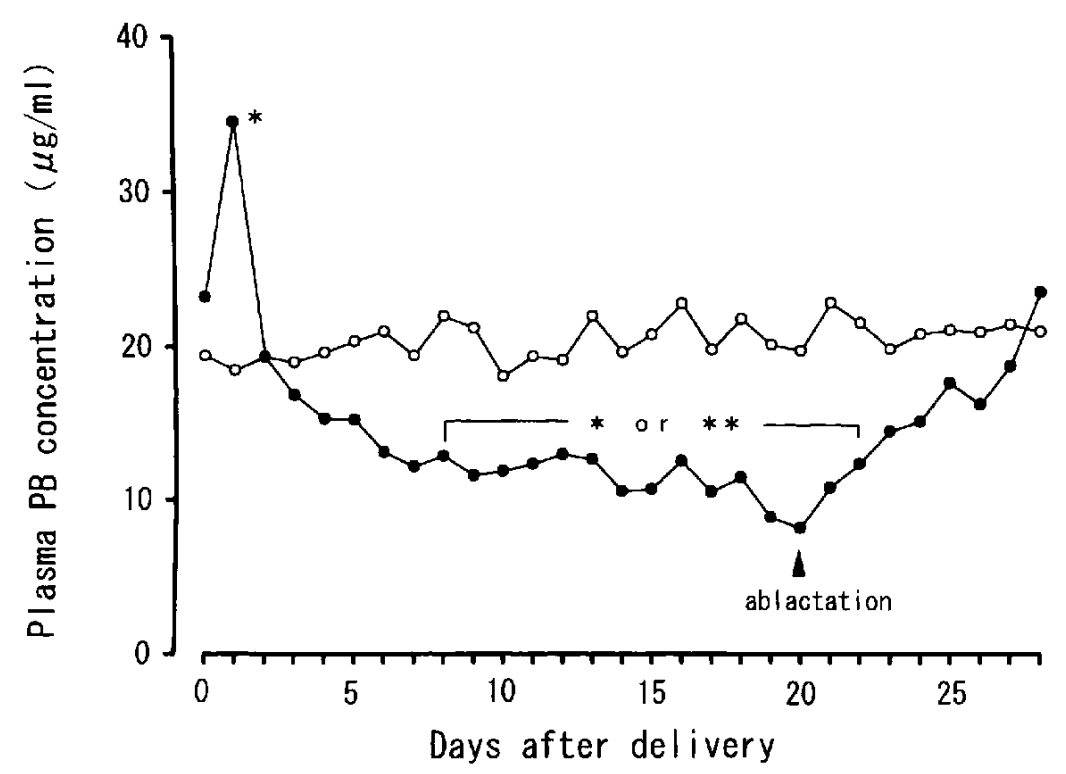

Fig. 1. Daily changes in plasma phenobarbital (PB) concentrations during lactation and after ablactation in female rats treated with PB. Blood was collected every morning before and during administration, and PB concentrations were measured by HPLC. Each point indicates the mean value. $O$, undelivered group $(n=3)$;, lactating group $(n=3) .{ }^{*} P<0.05,{ }^{* *} P<0.01$ vs undelivered group.

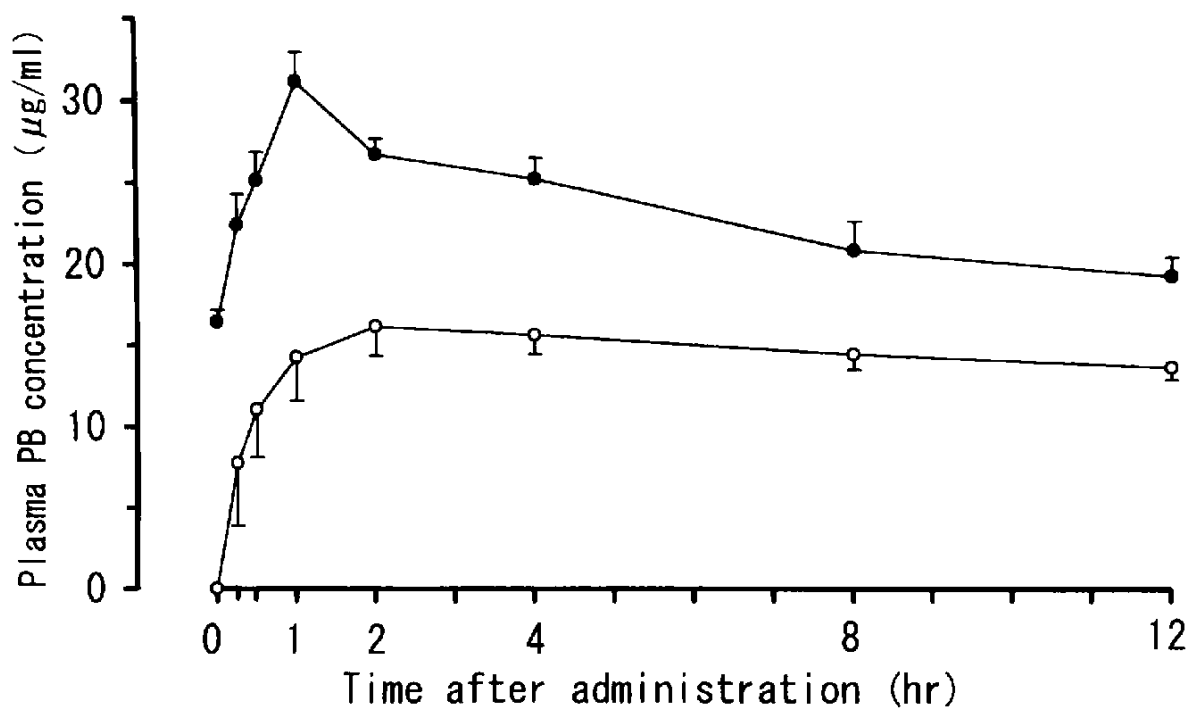

Fig. 2. Time-course changes in plasma $P B$ concentrations after a single oral $P B$ administration during early (2-4 days after delivery) lactation in rats treated chronically with or without $P B$. Each point indicates a mean \pm S.E.M. $O$, without $P B(n=3)$; , chronic PB $(n=3)$.

and then gradually decreased.

During mid (10-11 days after delivery) lactation in chronically PB-treated and untreated rats, the plasma PB concentrations rapidly increased to a maximum of 32.8 and $23.3 \mu \mathrm{g} / \mathrm{ml}$ at 2 and $1 \mathrm{hr}$, respectively, and then decreased faster than in the early stage of lactation (Fig. 3).

Figure 4 shows changes in the plasma PB concentra- tions following the oral administration of $P B(20 \mathrm{mg} / \mathrm{kg}$, p.o.) after ablactation (2-3 days after weaning from the mother). Plasma PB concentrations in chronically PBtreated and -untreated rats rapidly increased to a maximum of 46.2 and $23.9 \mu \mathrm{g} / \mathrm{ml}$ at $2 \mathrm{hr}$, respectively, and then gradually decreased in a manner similar to the timecourse changes during early lactation.

Pharmacokinetic parameters of PB in delivered and 


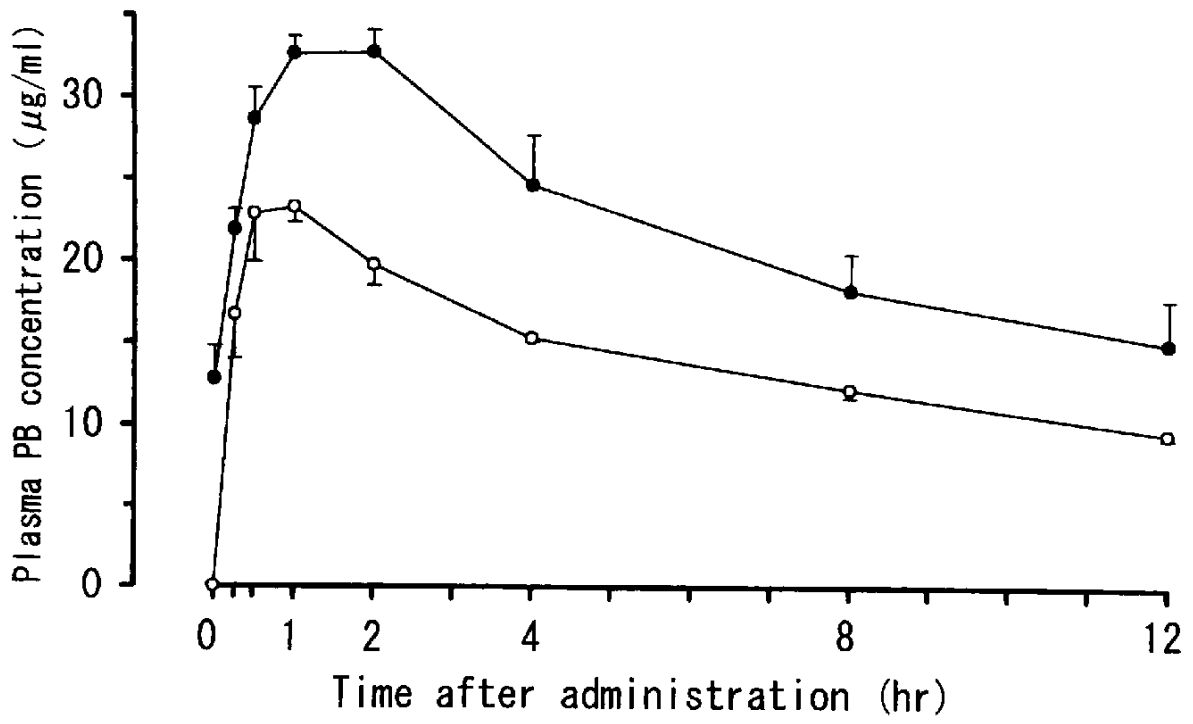

Fig. 3. Time-course changes in plasma PB concentrations after oral PB administration during mid (10-11 days after delivery) lactation in rats treated chronically with or without PB. Each point indicates a mean \pm S.E.M. $O$, without $P B$ ( $n=3$ ), , chronic PB $(\mathrm{n}=3)$.

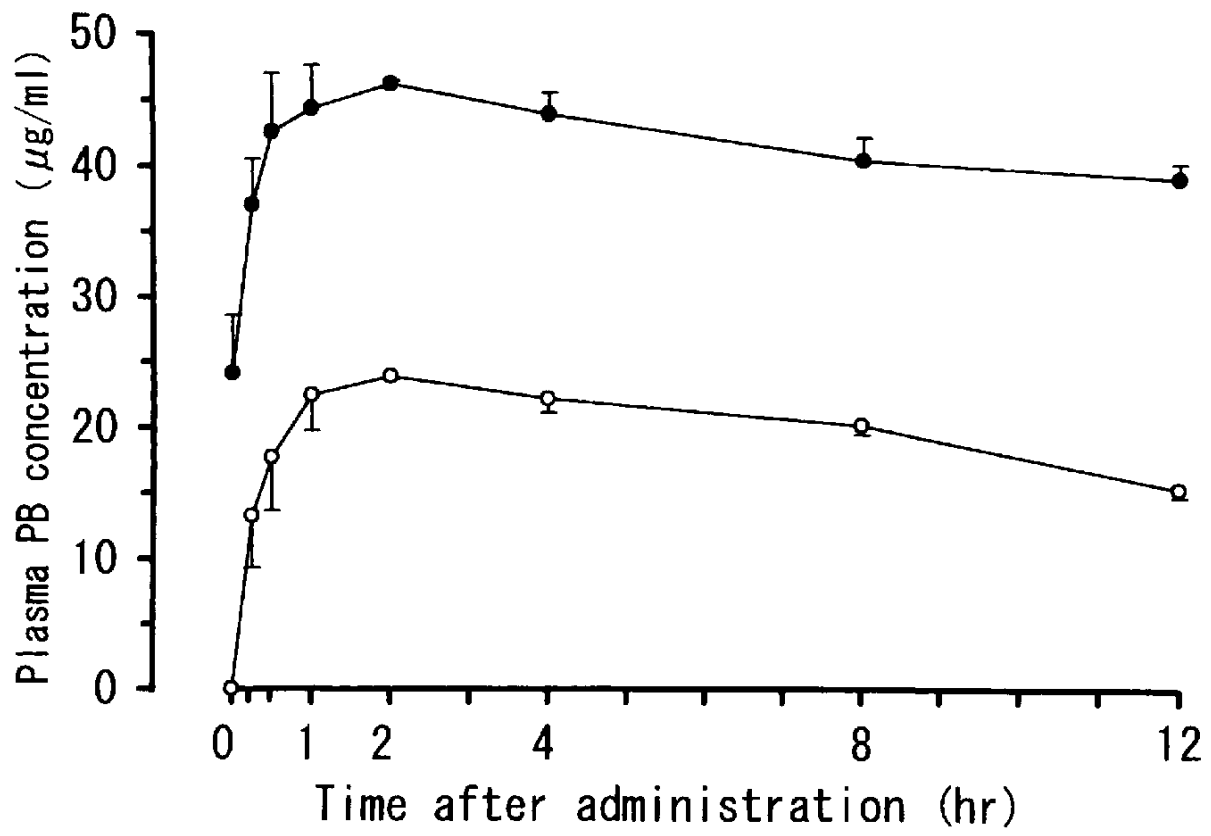

Fig. 4. Time-course changes in plasma $P B$ concentrations after a single oral $P B$ administration following ablactation (2-3 days after weaning) in rats treated chronically with PB. Each point indicates a mean \pm S.E.M. $\bigcirc$, without $P B$ ( $n=3$ ); , chronic PB $(n=3)$.

lactating rats are shown in Table 1 . In mid lactation, $\mathrm{C}_{\max }, \mathrm{AUC}_{0-12}$ and MRT decreased, when compared with the control rats (pre-delivery and non-lactating rats). Both $\mathrm{C}_{\max }$ and $\mathrm{AUC}_{0-12}$ in lactating rats were significantly lower than those in control rats. In the post-lactation rat, the pharmacokinetic parameters $\left(C_{\max }, \mathrm{AUC}_{0-12}\right)$ were almost at control levels.

\section{DISCUSSION}

The present study showed that a) chronic PB administration did not affect the body weight of lactating and undelivered rats; b) the plasma concentration of PB decreased gradually during lactation until weaning on the 20th day; c) after ablactation, plasma PB concentrations 
Table 1. Effect of lactation on pharmacokinetic parameters

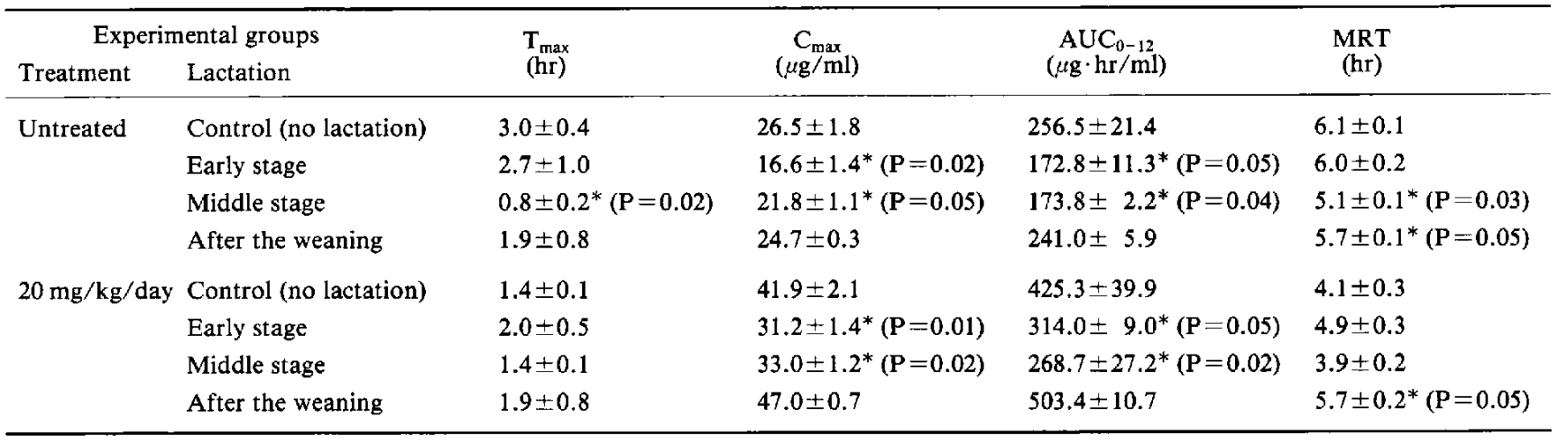

PB at a single dose of $20 \mathrm{mg} / \mathrm{kg}$ was administered orally by gavage to the chronically PB-treated groups. Data indicate means \pm S.E.M. calculated by the personal computer program MULTI. AUC and MRT values were calculated from 0 to $12 \mathrm{hr}$ after oral administration. Each asterisk indicates a significant difference from the control in each experimental group (paired $t$-test).

returned to pre-lactation levels and $d$ ) the $C_{\max }$ and $\mathrm{AUC}_{0-12}$ values significantly decreased during lactation. These results suggest that lactation causes a decrease in the plasma $P B$ concentration in rats.

Plasma PB concentrations of rats on the first day after the delivery were markedly higher than those of undelivered rats (Fig. 1). Because the PB dose was adjusted in proportion to the increasing body weight during pregnancy, to a fixed ratio throughout the experiment, and because body weight increased during late part of pregnancy, the increased plasma PB concentrations on the first day after delivery seemed to be due mainly to the acute loss of distribution volume, which had been supplied to the fetus.

Long-term PB administration induces the enzyme that metabolizes it (14). In fact, $T_{\max }$ and MRT was decreased by long-term PB administration (Table 1). Davis et al. (15) reported that hepatic enzyme levels alter during pregnancy. Therefore, long-term PB administration should affect pharmacokinetic parameters during lactation. The present findings that both $T_{\max }$ and MRT significantly decreased (Table 1) during long-term PB administration suggest enzyme induction. However, the pharmacokinetic parameters in PB-treated and -untreated groups were similar during lactation (Table 1). Thus, long-term PB administration does not affect pharmacokinetic parameters during lactation.

As shown in Table 1, during early and mid lactation in both chronically PB-untreated and PB-treated groups, $\mathrm{C}_{\max }$ and $\mathrm{AUC}_{0-12}$ values were significantly lower than those in the control rats. After ablactation, these pharmacokinetic parameters returned to control values. It is likely that the decreases in $\mathrm{T}_{\max }, \mathrm{C}_{\max }, \mathrm{AUC}_{0-12}$ and MRT mainly reflect $P B$ transfer to the increased lactation due to growing demands of the pups, and the increased values may be due to stopping lactation. Many investigators have reported that antiepileptic drug concentrations alter during pregnancy because of physiological changes in hormonal factors $(16)$, renal function $(16,17)$ and protein binding (16). The decrease in $\mathrm{T}_{\max }, \mathrm{C}_{\max }, \mathrm{AUC}_{0-12}$ and MRT during lactation and changes in MRT after weaning may be affected by physiological changes caused by pregnancy or by hormonal changes during lactation.

Recently, we reported that pregnancy itself does not affect plasma levels and pharmacokinetic parameters of PB when chronically administered if the dosage is fixed according to maternal body weight, which includes that of the fetus (12). In the present study, plasma PB concentrations in chronic PB-treated rats after delivery gradually decreased when the dosage was fixed according to maternal weight excluding that of the pups. Thus, we calculated the plasma PB concentrations when the dosage was determined according to the weight of the mother plus that of the pups. This calculation showed that plasma PB concentrations gradually elevated due to the increased weight of the offspring during late lactation (data not shown). Therefore, we corrected the plasma PB concentration using the human milk/plasma ratio of 0.35 reported by Kaneko et al. $(18,19)$, although we have no data on the milk/plasma ratio of PB concentrations in rats because measuring $\mathrm{PB}$ concentrations in rat milk is difficult. From this calculation, the corrected plasma PB concentrations were relatively constant during lactation. Thus, we suggest that plasma PB can be maintained at a constant concentration by adjusting the dose to fit the corrected body weight that includes a $35 \%$ increase to account for the weight of the pups.

In conclusion, the present study suggests that decreased plasma $\mathrm{PB}$ concentrations after delivery and changes in the pharmacokinetics of $\mathrm{PB}$ during the lactation in rats result from the transfer of $\mathrm{PB}$ to the offspring through maternal milk. The present results also suggest that the 
loss of PB during lactation reflects a constant PB concentration in the plasma of the lactating patient.

\section{REFERENCES}

1 Hanson LA, Hahn-Zoric M, Berndes M, Herias V and MattsbyBaltzer I: Breast feeding: Overview and breast milk immunology. Acta Paediatr Jpn 36, 557-561 (1994)

2 Lawrence PB: Breast milk. Best source of nutrition for term and preterm infants. Pediatr Clin North Am 41, 925-941 (1994)

3 Nanbu H: Psychological view of breast feeding. Syouni Igaku 22, 918-936 (1989) (in Japanese)

4 Nau H, Kuhnz W, Egger HJ, Ruting D and Helge H: Anticonvulsants during pregnancy and lactation: transplacental, maternal, and neonatal pharmacokinetics. Clin Pharmacokinet 7 , $508-543$ (1982)

5 Bjerkedal $\mathrm{T}$ : Outcome of pregnancy in women with epilepsy, Norway, 1967 to 1978: gestational age, birth weight, and survival of the newborn. In Epilepsy, Pregnancy, and the Child, Edited by Janz D, Dam M, Richens A, Bossi L, Helge H and Schmidt D, pp 175-178, Raven Press, New York (1982)

6 Hiilesmaa VK, Teramo K, Granström ML and Bardy AH: Fetal growth and antiepileptic drugs: preliminary results of the prospective Helsinki study. In Epilepsy, Pregnancy, and the Child, Edited by Janz D, Dam M, Richens A, Bossi L, Helge H and Schmidt D, pp 203-205, Raven Press, New York (1982)

7 Janz D: On major malformations and minor anomalies in the offspring of parents with epilepsy: review of the literature. In Epilepsy, Pregnancy, and the Child, Edited by Janz D, Dam M, Richens A, Bossi L, Helge $H$ and Schmidt D, pp 211-222, Raven Press, New York (1982)

8 Seth PK, Alleva FR, Takagi S, Yen-Koo HC and Balazs T: Brain neurotransmitter receptor alterations in offspring of rats exposed to phenobarbital, phenytoin or their combination during pregnancy. Neurotoxicology 8, 45-54 (1987)

9 Bardy AH: Incidence of seizures during pregnancy, labor and puerperium in epileptic women: a prospective study. Acta Neurol Scand 75, 356-360 (1987)

10 Suzuki K, Kaneko S, Saito F, Kubota S, Otani K, Hayashi S and Takeuchi I: Serum levels of antiepileptic drugs in neonates and in their mothers with epilepsy during puerperium. In Antiepileptic Drug and Pregnancy, Edited by Sato T and Shinagawa S, pp 20-32, Excerpta Medica, Amsterdam (1984)

11 Moriyama M, Furuno K, Oishi R and Gomita Y: Simultaneous determination of primidone and its active metabolites in rat plasma by high-performance liquid chromatography using a solid-phase extraction technique. J Pharm Sci 83, 1751-1753 (1994)

12 Moriyama M, Domoto H, Yamashita S, Furuno K, Oishi R, Kawasaki $\mathrm{H}$ and Gomita $\mathrm{Y}$ : Effect of pregnancy on plasma phenobarbital concentrations in rats. Acta Med Okayama 49, $237-240$ (1995)

13 Yamaoka $\mathrm{K}$, Tanigawara $\mathrm{Y}$, Nakagawa $\mathrm{T}$ and Uno T: A pharmacokinetic analysis program (MULTI) for microcomputer. J Pharmacobiodyn 4, 879-885 (1981)

14 Richens A: Liver enzyme induction by antiepileptic drugs: its clinical significance. In Anticonvulsant Drugs and Enzyme Induction, Edited by Richens $A$ and Woodfort FP, pp 3-12, Elsevier, Amsterdam (1976)

15 Davis M, Simmons CJ, Dordoni B, Maxwell JD and Williams $\mathrm{R}$ : Induction of hepatic enzyme during normal pregnancy. $\mathrm{J}$ Obstet Gynaecol Br Cwlth 80, 690-694 (1973)

16 Krauer B and Krauer F: Drug kinetics in pregnancy. Clin Pharmacokin 2, 167-181 (1977)

17 Kochenour NK, Emery MG and Sawchuk RJ: Phenytoin metabolism in pregnancy. Obst Gynecol 56, 577-582 (1980)

18 Kaneko S, Suzuki K and Sato T: The levels of anticonvulsants in breast milk. Br J Clin Pharm 7, 624-627 (1979)

19 Kaneko S, Suzuki K, Sato T, Ogawa Y and Nomura Y: The problem of antiepileptic medication in the neonatal period: Is breast feeding advisable? In Epilepsy, Pregnancy, and the Child Edited by Janz D, Dam M, Richens A, Bossi L, Helge H and Schmidt D, pp 343-348, Raven Press, New York (1982) 